\title{
Syringe access for the prevention of blood borne infections among injection drug users Sharon Stancliff1, Bruce Agins ${ }^{1}$, Josiah D Rich*2 and Scott Burris ${ }^{3}$
}

Address: ${ }^{1}$ AIDS Institute, New York State Department of Health, 5 Penn Plaza, 1st Floor, New York, New York 10001, USA, ${ }^{2 T h e ~ M i r i a m ~}$ Hospital,164 Summit Avenue, Providence, RI 02906, USA and ${ }^{3}$ Temple University Beasley School of Law, 1719 N Broad Street Philadelphia, PA 19122, USA

Email: Sharon Stancliff - sls14@ health.state.ny.us; Bruce Agins - jrich@lifespan.org; Josiah D Rich* - Bda01@health.state.ny.us; Scott Burris - Scott.burris@temple.edu

* Corresponding author

Published: 21 November 2003

BMC Public Health 2003, 3:37
Received: I5 July 2003

Accepted: 21 November 2003

This article is available from: http://www.biomedcentral.com/I47I-2458/3/37

(c) 2003 Stancliff et al; licensee BioMed Central Ltd. This is an Open Access article: verbatim copying and redistribution of this article are permitted in all media for any purpose, provided this notice is preserved along with the article's original URL.

\begin{abstract}
Background: Approximately one-third of acquired immunodeficiency syndrome cases in the United States are associated with the practice of sharing of injection equipment and are preventable through the once-only use of syringes, needles and other injection equipment.

Discussion: Sterile syringes may be obtained legally by 4 methods depending on the state. They may be purchased over the counter, prescribed, obtained at syringe exchange programs or furnished by authorized agencies. Each of these avenues has advantages and disadvantages; therefore, legal access through all means is the most likely way to promote the use of sterile syringes.

Summary: By assisting illicit drug injectors to obtain sterile syringes the primary care provider is able to reduce the incidence of blood borne infections, and educate patients about safe syringe disposal. The provider is also able to initiate discussion about drug use in a nonjudgmental manner and to offer care to patients who are not yet ready to consider drug treatment.
\end{abstract}

\section{Background}

Approximately one-third of acquired immunodeficiency syndrome cases in the United States are associated with the practice of sharing of injection equipment [1]. Injection drug use is also the principal mode of hepatitis $\mathrm{C}$ transmission. The majority of these infections can be prevented through the once-only use of syringes, needles and other injection equipment as recommended by the U.S. Department of Health and Human Services [2].

There is strong evidence that injection drug users (IDUs) are capable of altering their injecting behaviors, thus preventing the spread of disease. Injection drug users began to hear educational messages about transmission of infec- tious diseases through injection and means of prevention in the late 1980's. In New York City bleach kits were distributed and in 1992 several syringe exchange programs (SEPs) began legal operation. Between 1990 and 1997 IDUs in New York City reported significant declines in risky injection practices [3] and the prevalence of HIV among IDUs dropped from $50 \%$ to $30 \%$ by 2000 [4]. These data indicate that given necessary education and tools, drug users can make significant changes in behavior. In light of numerous reports documenting the efficacy of syringe exchange [5-7] many professional associations have called for the elimination of barriers that limit access to sterile syringes as an important way to further reduce transmission of infections through injection drug use. 
Table I: States in which Physician Prescription of Sterile Injection Equipment and Pharmacy Sale of Prescribed Syringes are Clearly Legal to Prevent Disease Transmission

\begin{tabular}{lllll}
\hline AK & CA & CO & CT & HI \\
IL & IN & LA & MA & ME \\
MI & MN & MT & NV & NH \\
NJ & NM & NY & OR & PA \\
PR & RI & SC & TN & VA \\
WA & WV & WI & & \\
\hline
\end{tabular}

Table 2: States with Syringe Exchange Programs* Receive public funding ** Shut down

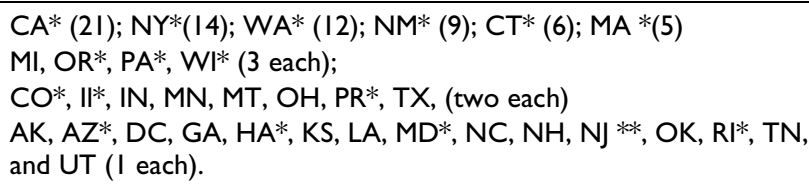

*Receive public funding ** Shut down

Sterile syringes may be obtained legally by 3 methods although their availability varies considerably from state to state. They can be purchased over the counter, prescribed, or obtained at SEPs or other authorized agencies. Many states do not require prescriptions for syringes and since the beginning of the HIV epidemic, twelve states (Connecticut, Hawaii, Illinois, Maine, Minnesota, New Hampshire, New Mexico, New York, Oregon, Rhode Island, Washington, and Wisconsin ${ }^{8}$ ) have changed their syringe access laws making it possible to obtain syringes over the counter. In many states, syringes can be legally prescribed by health care professionals for drug injection by IDUs (Table 1) [8,9]. As of 1998, at least 131 SEPs were operating in 31 states (Table 2) [10]. Not all of these have a clear legal basis. Twelve states and the District of Columbia have affirmatively authorized SEPs. Ten jurisdictions have passed statutes establishing programs (Connecticut, District of Columbia, Hawaii, Maine, Maryland, New Mexico, Rhode Island and Vermont) or authorizing local governments to do so (California and Massachusetts). In New York, syringe exchange programs are authorized by the Commissioner of Health, exercising power granted in the paraphernalia law to waive its application. In the state of Washington, local health officials secured a declaratory judgement from the state Supreme Court holding that the paraphernalia law did not prohibit them from authorizing SEPs, a ruling that was later codified by the legislature. Each of these options has its own strengths and limitations; different groups of IDUs are more likely to use pharmacies while others are more likely to use syringe exchange programs [11]. The availability of all options is the most effective way to provide maximum access for injection drug users. This article describes and discusses the various options for legal syringe access for injection drug users.

\section{Discussion Syringe Prescription}

The American Medical Association endorsed prescription of syringes by physicians through a policy adopted at its Annual Meeting held in June 2000:

" ... the American Medical Association strongly supports the ability of physicians to prescribe syringes and needles to patients with injection drug addiction in conjunction with addiction counseling in order to help prevent the transmission of contagious diseases." [12]

Until recently it was widely assumed that the laws in many states prohibited the prescription of syringes for the purpose of injecting illicit drugs. In August 2000 the Project on Harm Reduction in the Health Care System from Temple University Law School released a comprehensive study of syringe prescription laws in all 50 states concluding that prescription of syringes for the prevention of disease is legal in many states. The barriers to prescription in each state are also discussed. These documents, updated to include legal changes through June 2003, may be found at: $\quad$ http://www.temple.edu/lawschool/aidspolicy/ default.htm[13].

The prescription of syringes can potentially prevent bloodborne disease by providing a sufficient supply of clean syringes to injectors. Furthermore it offers an opportunity to attract and retain a population at risk of many health problems which may otherwise be difficult to engage in care. By offering syringes, the prescriber makes it clear that he or she is concerned about the patient's well-being even if drug use continues. This concern can promote honest dialogue about drug use, perhaps encouraging a patient to acknowledge for the first time to the physician that they are using drugs. In other cases, it opens the door to acceptance of drug treatment [14] or other interventions to reduce the harm of continued drug use, such as the provision of take-home naloxone for use in the event of overdose [15].

The chief drawbacks to the prescription of syringes in states where the practice is legal are the lack of explicit authorization for the practice and the related perception that law enforcement officials opposed to the practice would find some legal basis to prosecute physicians who prescribe syringes [13]. Another drawback to prescription of syringes is that drug users report a lack of access to primary health care, often because they have no health insurance $[16,17]$. They may also be deterred by the perception that many physicians would prefer not to care for them because of their drug use [18]. 


\section{Non-prescription Pharmacy Sales}

Pharmacies provide another option for syringe access through over-the-counter sales. They are easy to access in most communities, and have long hours of operation. Pharmacists are trained health care professionals who can offer health education to their customers. Syringes are available anonymously on a walk-in basis. Pharmacy sales of syringes in Connecticut and Minnesota were evaluated and found to be effective in reducing risky injection behaviors $[19,20]$ and were not shown to increase drug use [19]. Pharmacy sales also provide an impetus to promote safe disposal [21,22]. However, not all pharmacies in states allowing sales choose to sell syringes without a prescription, perhaps because they do not want drug users as clientele or are concerned that they may promote drug use [23].

\section{Free distribution by Syringe Exchange Programs}

Syringe exchange programs are staffed by persons who have significant expertise in addressing the needs facing injection drug users. In addition to syringes, IDUs may also receive a variety of services such as education about safer injection, proper syringe disposal, referrals to drug treatment, referrals to medical care, and public health services such as HIV counseling and testing and tuberculosis screening [10]. Like pharmacies, they require no appointment or identification. Because they rely on exchange of used syringes for sterile ones syringe disposal is also an integral part of the service. Syringe exchange programs have been extensively evaluated and have been found to be effective in preventing disease without promoting drug use $[5-7,24]$; they have also been found to be cost effective [25]. The chief drawback to SEPs is their lack of accessibility; there are approximately 130 exchanges in the entire United States. SEPs also require that participants carry and return medical waste containing drug residue that may put them at risk of arrest [26]. Also, SEPs are not routinely staffed by licensed health professionals available during all hours of operation.

\section{Free or Fee-Based Provision by Clinicians}

In New York State, under a current demonstration program, hospitals, clinics and those practitioners authorized to prescribe syringes are able to furnish (provide access either through sales or at no cost) up to 10 syringes per encounter. Like prescribing syringes, this option opens a dialogue with a clinician about drug use. When health care providers offer this service, the step of visiting the pharmacy is eliminated, which may be important when the patient has little money or wishes to maintain confidentiality about his or her drug use. The program is currently under evaluation, however potential drawbacks include the fact that currently no specific funding is allocated for the furnishing of syringes and as of December 2002 only 41 non-pharmacy providers had registered to
Table 3: Steps for physicians caring for active injection drug users

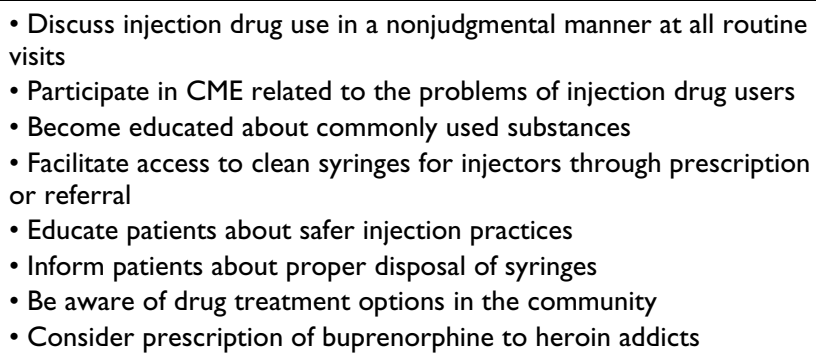

provide syringes. Furthermore 10 syringes, if used only once per injection, will not last a regular drug user long; the average number of injections per day is estimated to be 2.8 [27].

\section{Treating Injection Drug Users}

In addition to preventing bloodborne infections, providing illicit drug injectors access to sterile syringes both directly and by referral presents an important opportunity to improve communication between medical providers and their drug using patients [14]. Physicians have been noted to be uncomfortable treating patients with substance abuse disorders. Some of this may be attributed to a lack of training in the causes and treatments of substance abuse [18]. Furthermore, medical providers are generally trained to encourage abstinence only, whether or not the patient desires it or is able to achieve it. As a basic medical text states, "The goals of treatment for persons who are dependent on psychoactive substances can be divided into three major components: the achievement of abstinence, relapse prevention, and rehabilitation." [28]. However, physicians are most likely to encounter drug-using patients who are unable or unwilling to achieve abstinence, unable to access treatment or who continue to use drugs despite treatment. The discrepancy between what is taught formally in medical schools and what is encountered in practice may further contribute to the dissatisfaction physicians experience in caring for drug users. There are a variety of ways that a primary care provider can provide care for active drug users (Table 3). Medical schools should plan curricula to close this gap while practicing physicians should be encouraged to seek out Continuing Medical Education programs to become further educated about the problems of injection drug users.

Even patients who wish to stop using drugs face obstacles to achieving that goal. There are insufficient treatment slots in most parts of the country. For example, while methadone maintenance has been shown to be a highly effective treatment for heroin, the number of available slots is sufficient to serve at most $30 \%$ of heroin addicts 
[29]. The recent approval of office based treatment of opioid addiction with buprenorphine may alleviate this shortage; physicians treating even a small number of opioid addicts may benefit their patients by becoming qualified to provide this medication $[30,31]$.

Cocaine treatment slots are also scarce and furthermore, while many compulsive users cease or moderate use, more effective therapeutic modalities for cocaine addiction are desperately needed [32]. When the physician can offer additional meaningful interventions, such as providing syringes to prevent infection and education about how to reduce other risks, he or she may feel increased satisfaction in caring for drug using patients. Education is key; these patients may not otherwise have an opportunity to discuss drug use and injection with anyone knowledgeable about its health risks. Education may be needed about safe injection, about the substances used, and about options for treatment. When patients can be honest about their drug use they can ask questions about possible drug interactions and be more open about how drug use may impact their health.

Drug users also have medical needs, both for routine care and for care related to drug use such as HIV, the need for hepatitis B vaccine, or treatment for hepatitis C [33]. Improved rapport with medical providers may facilitate treatment and prevention activities. Finally, increased healthcare utilization, including ambulatory medical care, is also associated with entry into drug treatment. Increased willingness to treat drug users that leads to attendance at medical appointments by drug users may therefore also lead to reductions in drug use for some patients [34].

Major public health and economic benefits also accrue from the prevention of bloodborne infections among IDUs. For example, HIV may be transmitted to sex partners and to children of an infected drug user. HIV infection is expensive; the lifetime cost of one infection is estimated to be at least $\$ 195,000$ [35], equal to the cost of well over 2 million syringes. Increasing access to sterile injection equipment is included in recent Centers for Disease Control recommendations on how primary care providers can incorporate prevention of HIV transmission when providing care to persons living with HIV [36]. Additionally, when the use of syringes is discussed with patients, proper disposal of used syringes may also be addressed. Proper syringe disposal is poorly managed among both diabetics and injection drug users [26,37]; education of both groups may be beneficial. Legal access to syringes may also contribute to proper disposal as drug users report being more likely to dispose of syringes safely when obtained legally [38]. In New York State pharmacy sales of syringes have not resulted in an increase in syringes on the street or improperly disposed of in the trash $[39,40]$. Patient education materials such as those provided by the American Medical Association can also facilitate education about disposal [41].

Some may question whether providing access to syringes for the harmful act of injecting illicit drugs is ethical. For example, it may be argued that the potential for harm from injection violates the principle of nonmaleficence. However the prevalence of bloodborne infections attests to the fact that lack of a sterile syringe is not a deterrent to injection drug use and that the likelihood of harm to the patient and his or her contacts is high in the absence of sterile syringe access. In fact some might argue that failure to provide access could be considered "failure to guard against risks of harm to others" [42], and a violation of the principle of nonmaleficence. Ensuring access to sterile syringes clearly upholds the principle of beneficence as it has the potential to prevent irreversible harm, not only to the recipient but to the general public by reducing transmission to sexual partners and children of injection drug users. In addressing ethical issues, the Project on Harm Reduction concludes that not only is provision of sterile syringes to drug users ethical, but also that "physicians treating patients who inject drugs are, at least in the absence of legal limits, obliged by their own professional standards to consider providing this care to patients who need it." [13]

Communities wishing to achieve maximal availability of sterile syringes may opt to offer all avenues of access to sterile syringes. Injection drug users would be more likely to use a sterile syringe each time they inject if multiple sources were available for procuring them. All primary care providers should be aware of the resources that are available for the provision of syringes and their proper disposal in their communities. Those treating significant numbers of injection drug users may wish to become active in promoting additional resources, and advocate for syringe availability in areas with limited access. By increasing access to sterile syringes through all potential methods bloodborne diseases may be effectively prevented, which will benefit not only injection drug users but also the wider public. Both economic benefits and enhanced public health will be realized.

\section{Summary}

Legal access to sterile syringes for injection drug users can decrease syringe sharing and disease transmission. Sterile syringes may be obtained legally by 3 methods depending on the state. Each of these avenues has advantages and disadvantages; therefore, legal access through all means is the most likely way to promote the use of sterile syringes. By assisting illicit drug injectors to obtain sterile syringes the primary care provider is able to reduce the incidence of 
blood borne infections, and educate patients about safe syringe disposal. The provider is also able to initiate discussion about drug use in nonjudgmental manner and to offer care to patients who are not yet ready to consider drug treatment.

* American Academy of Family Practice [43], American Academy of Pediatrics [44], American Bar Association [45], American Medical Association [46], American Public Health Association [47], American Pharmaceutical Association [46], Association of State and Territorial Health Officials [46], National Alliance of State and Territorial AIDS Officials [46], National Association of Boards of Pharmacy [46]

\section{Competing interests}

None declared.

\section{Authors' contributions}

SS wrote the initial and final drafts. SB provided legal expertise. JR and BA contributed additional concepts and instructive comments. All authors read and approved the final manuscript.

\section{Acknowledgements}

Dr. Rich's involvement in this project was supported by grant number P30Al-42853 from the National Institutes of Health, Center for AIDS Research (NIH CFAR), and grant number 10630-26-EG from the American Foundation for AIDS Research (AMFAR). Mr. Burris's work is supported by a grant from the Substance Abuse Policy Research Program of the Robert Wood Johnson Foundation. Its contents are solely the responsibility of the authors and do not necessarily represent the official views of the awarding Agencies.

\section{References}

I. CDC: HIVIAIDS surveillance report, 2000. Atlanta, Georgia. US Department of Health and Human Services, Public Health Service, CDC 2000, 12:I [http://www.cdc.gov/hiv/stats/hasr /20I.pdf]. Accessed II/ 14/03

2. U.S. Department of Health and Human Services, Public Health Service: HIV prevention bulletin: Medical advice for persons who inject illicit drugs. [http://www.cdc.gov/idu/pubs/hiv prev.htm]. (Accessed II//4/03)

3. Des Jarlais DC, Perlis T, Friedman SR, Chapman T, Kwok J, Rockwell $R$ et al:: Behavioral risk reduction in a declining HIV epidemic: injection drug users in New York City, 1990-1997. Am J Public Health 2000, 90(7): III2-1II6.

4. Des Jarlais DC: Unexpected Success in HIV Prevention for Injecting Drug Users in New York City. 200I National HIV Prevention Conference Atlanta 200I.

5. Gibson DR, Flynn NM, Perales D: Effectiveness of syringe exchange programs in reducing HIV risk behavior and HIV seroconversion among injecting drug users. AIDS I5(II):|329-1341. 2001 Jul 27

6. Lurie P, Reingold AL, Bowser B et al.: The public health impact of needle exchange programs in the United States and abroad San Francisco, University of California; 1993.

7. Normand J, Blaho D, Moses LE, eds: Preventing HIV Transmission : The Role of Sterile Needles and Bleach Washington, DC: National Academy Press; 1995.

8. Burris $\mathrm{S}$, Lurie $\mathrm{P}, \mathrm{Ng} \mathrm{M}$ : Harm reduction in the health care system: the legality of prescribing and dispensing syringes to drug users. Health Matrix Clevel 200I, I I (I):5-64.
9. Burris S, Lurie P, Abrahamson D, Rich JD: Physician prescribing of sterile injection equipment to prevent HIV infection: time for action. Ann Intern Med I33(3):2 18-226. 2000 Aug I

10. CDC: Update: Syringe Exchange Programs United States, 1998. MMWR 200I, 50:384-387.

II. Miller CL, Tyndall M, Spittal P, Li K, Palepu A, Schechter MT: Risktaking behaviors among injecting drug users who obtain syringes from pharmacies, fixed sites, and mobile van needle exchanges. J Urban Health 2002, 79(2):257-265.

12. AMA website [http://www.ama-assn.org/ama/pub/category/ 1808.html]. Accessed I I//4/03

13. Burris S: Project On Harm Reduction. In The Health Care System Temple University of the Commonwealth System of Higher Education Beasley School of Law [http://www.temple.edu/lawschool/aidspolicyl default.htm]. Accessed II/I4/03

14. Rich JD, Macalino GE, McKenzie M, Taylor LE, Burris S: Syringe prescription to prevent HIV infection in Rhode Island: a case study. Am J Public Health 200I, 9 I (5):699-700.

15. Burris $S$, Norland J, Edlin BR: Legal aspect of providing naloxone to heroin users in the United States,. Int'l J Drug Policy 200I, I 2:237-248

16. O'Connor PG, Molde S, Henry S, Shockcor WT, Schottenfeld RS: Human immunodeficiency virus infection in intravenous drug users: a model for primary care. Am J Med 1992, 93:382-386.

17. Stancliff S, Salomon N, Perlman DC, Russell PC: Provision of influenza and pneumococcal vaccines to injection drug users at a syringe exchange. J Subst Abuse Treat 2000, 18(3):263-265.

18. Miller NS, Sheppard LM, Colenda CC, Magen J: Why physicians are unprepared to treat patients who have alcohol- and drugrelated disorders. Acad Med 200I, 76(5):4I0-4I8.

19. Groseclose SL, Weinstein B, Jones TS, Valleroy LA, Fehrs LJ, Kassler WJ: Impact of increased legal access to needles and syringes on practices of injecting-drug users and police officers - Connecticut, 1992-1993. J Acquir Immune Defic Syndr Hum Retrovirol I O(I):82-89. I995 Sep I

20. Cotten-Oldenburg NU, Carr P, DeBoer JM, Collison EK, Novotny G: Impact of pharmacy-based syringe access on injection practices among injecting drug users in Minnesota, 1998 to 1999. J Acquir Immune Defic Syndr. 27(2): I83- 192. 200I Jun I

21. Klein SJ, Estel GR, Candelas AR, Plavin HA: Promoting safe syringe disposal goes "hand in hand" with expanded syringe access in New York State. J Am Pharm Assoc (Wash) 2002, 42(6 Suppl 2):SI05-SI07.

22. Jones TS, Coffin PO: Preventing blood-borne infections through pharmacy syringe sales and safe community syringe disposal. J Am Pharm Assoc (Wash) 2002, 42(6 Suppl 2):S6-59.

23. Linas BP, Coffin PO, Backes G, Vlahov D: New York State pharmacists' attitudes toward needle and syringe sales to injection drug users before implementation of syringe deregulation. J Urban Health 2000, 77(4):768-780.

24. Drucker E, Lurie $P$, Wodak A, Alcabes P: Measuring harm reduction: the effects of needle and syringe exchange programs and methadone maintenance on the ecology of HIV. AIDS 1998, I2(Suppl A):S217-S230.

25. Laufer FN: Cost-effectiveness of syringe exchange as an HIV prevention strategy. J Acquir Immune Defic Syndr 28(3):273-278. 2001 Nov I

26. Macalino GE, Springer KW, Rahman ZS, Vlahov D, Jones TS: Community-based programs for safe disposal of used needles and syringes. J Acquir Immune Defic Syndr Hum Retrovirol I998, I8(SuppI I):SIII-SII 9 .

27. Lurie $P$, Jones TS, Foley J: A sterile syringe for every drug user injection: how many injections take place annually, and how might pharmacists contribute to syringe distribution? J Acquir Immune Defic Syndr Hum Retrovirol 1998, I 8(Suppl I):S45-S5I.

28. Hyman SE: Drug Abuse and Addiction. in Scientific American Medicine Edited by: Federman DG. Web MD Corporation; $200 \mathrm{I}$.

29. Barnett PG, Hui SS: The cost-effectiveness of methadone maintenance. Mt Sinai J Med 2000, 67(5-6):365-374.

30. Fudala PJ, Bridge TP, Herbert S, Williford WO, Chiang CN, Jones K, Collins J, Raisch D, Casadonte P, Goldsmith RJ, Ling W, Malkerneker $U$, McNicholas L, Renner J, Stine S, Tusel D: Buprenorphine/ Naloxone Collaborative Study Group. Office-based treatment of opiate addiction with a sublingual-tablet formula- 
tion of buprenorphine and naloxone. $N$ Engl J Med 349(10):949-959. 2003 Sep 4

31. [http://buprenorphine.samhsa.gov]. Accessed II//4/03

32. Government Accounting Office: Drug Abuse: Research Shows Treatment Is Effective, but Benefits May Be Overstated. 1998 [http://www.druglibrary.org/schaffer/GOVPUBS/gao/pdf28.pdf]. Accessed I I/I4/03

33. Brown LS Jr, Hickson MJ, Ajuluchukwu DC, Bailey J: Medical disorders in a cohort of New York city drug abusers: much more than HIV disease. J Addict Dis 1993, I 2(4): I I-27.

34. Strathdee SA, Celentano DD, Shah N, Lyles C, Stambolis VA, Macalino $G$ et al:: Needle-exchange attendance and health care utilization promote entry into detoxification. J Urban Health 1999, 76(4):448-460.

35. Holtgrave DR, Pinkerton SD: Updates of cost of illness and quality of life estimates for use in economic evaluations of HIV prevention programs. J Acquir Immune Defic Syndr Hum Retrovirol 1997, 16:55-61.

36. Centers for Disease Control and Prevention: Incorporating HIV prevention into the medical care of persons living with HIV: recommendations of CDC, the Health Resources and Services Administration, the National Institutes of Health, and the HIV Medicine Association of the Infectious Diseases Society of America. MMWR 2003, 52:RRI2.

37. Bouhanick B, Hadjadj S, Weekers L: What do the needles, syringes, lancets and reagent strips of diabetic patients become in the absence of a common attitude? About 1070 questionnaires in diabetic clinics. Diabetes Metab 2000, 26(4):288-293.

38. Burris S, Welsh J, Ng M, Li M, Ditzler A: State syringe and drug possession laws potentially influencing safe syringe disposal by injection drug users. J Am Pharm Assoc (Wash) 2002, 42(6 Suppl 2):S94-S98.

39. Fuller CM, Ahern J, Vadnai L, Coffin PO, Galea S, Factor SH et al: Impact of increased syringe access: preliminary findings on injection drug user syringe source, disposal, and pharmacy sales in Harlem, New York. J Am Pharm Assoc (Wash) 2002, 42(6 Suppl 2):S77-S82.

40. Lawitts S: Needle sightings and on-the-job needle-stick injuries among New York City Department of Sanitation Workers. J Am Pharm Assoc (Wash) 2002, 42(6 Suppl 2):S92-S93.

41. American Medical Association: Sharps Disposal Guidelines for Your Patients. [http://www.ama-assn.org/ama/pub/article//8082197.html]. Accessed II//4/03

42. Beauchamp TL, Childress JF: Principles of Biomedical Ethics pages. 4th edition. Oxford University Press; 1994.

43. Substance Abuse and Addiction, AAFP Policies on Health Issues American Academy of Family Practice 1998 [http:// www.aafp.org/x7096.xml]. Accessed I I//4/03

44. Reducing the risk of human immunodeficiency virus infection associated with illicit drug use. American Academy of Pediatrics. Provisional Committee on Pediatric AIDS. Pediatrics 1994, 94(6 Pt I):945-947.

45. Burris S, ed: Deregulation of Hypodermic Needles and Syringes as a Public Health Measure: A Report on Emerging Policy and Law in the United States. American Bar Association 2001 .

46. HIV prevention and access to sterile syringes. Joint letter issued by the American Medical Association, American Pharmaceutical Association, Association of State and Territorial Health Officials, National Association of Boards of Pharmacy, National Alliance of State and Territorial AIDS Directors 1999 [http://www.nastad.org/PublicPolicyResources/ HIVPrevSterileSyrines.pdf]. Accessed II//4/03)

47. Syringe and Needle Exchange and HIV Disease American Public Health Association, I/I/94 [http://www.apha.org/legisla tive/policy/policysearch/index.cfm?fuseaction=view\&id=8I] Accessed II//4/03

\section{Pre-publication history}

The pre-publication history for this paper can be accessed here:

http://www.biomedcentral.com/1471-2458/3/37/prepub

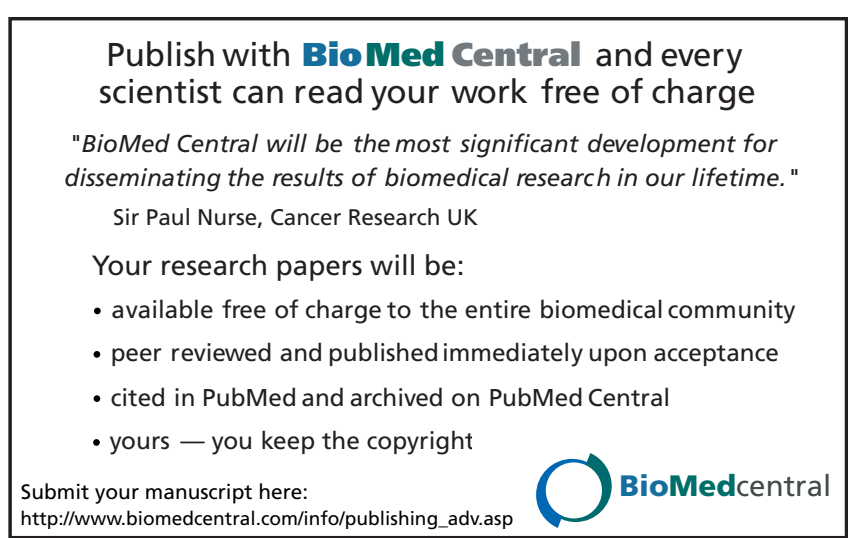

